\title{
Techniques in Direct Composite Restoration
}

\author{
Karthik D Yadav ${ }^{*}$, R Shesha Prasad ${ }^{2}$, Harika Chaganti ${ }^{3}$, Mohammed Saleem $^{4}$ and Anuradha Pai ${ }^{5}$ \\ ${ }^{1}$ Department of Oral Medicine and Radiology, Master of Dental surgery, India \\ ${ }^{2}$ Department of Oral Medicine and Radiology, Oxford Dental college, India
}

${ }^{3}$ Hospital management, India

${ }^{4}$ Department of Prosthodontics, Master of Dental surgery, India

${ }^{5}$ Department of Oral Medicine and Radiology, Oxford Dental college India

*Corresponding author: Karthik D Yadav, Department of Oral Medicine and Radiology, Master of Dental surgery, India

\begin{abstract}
Composite restorations have made their presence felt and also have solidified their position in the field of dentistry because of their esthetic varieties, longer life and their capability to provide an instant result which may sometimes be almost equivalent to ceramic restorations. However, there are many disadvantages like technique sensitive, polymerization shrinkage, inadequate dry area to work causing failure and inadequate light curing (time and depth) being some of them.
\end{abstract}

\section{Introduction}

Aesthetics are of great significance since a long era, as it attributes to a beautiful smile. The appropriate shape, position, color of the teeth are some of the factors which form an integral part the smile, which is accomplished by the use of modern restorative materials and techniques. These materials are color matched and at the same time also have the capability to be prepared onto the desired shape and form. Composite restorations have made their presence felt ominously and also have solidified their position in the field of dentistry because of their esthetic varieties, longer life and their capability to provide an instant result which may sometimes be almost equivalent to laboratory based ceramic restorative materials [1-4]. Advantage's such as minimal cavity preparation with instant restoration rendering immediate results has been the primary reason for its use when compared to the use of the other restorative materials. However, it is also very important to weigh the disadvantages against the advantages. In composites, polymerization shrinkage which in turn leads to loss of cohesion and adhesion of composite to the tooth is the key disadvantage, which makes its use vulnerable [5-10]. Polymerization shrinkage is dependent on content of the filler, water sorption, degree of conversion, modulus of elasticity, source of light and their variables [10]. Polymerization shrinkage can be considerably reduced by the restorative techniques followed by the physician. Placing restorative material in increments reduces the amount of shrinkage than when placed as a bulk and cured $[10,11]$. Hence, in this manuscript the various techniques of composite restoration have been enumerated for a better understanding and a favorable treatment outcome.

\section{Techniques for Direct Composite Restoration}

\section{Bulk Technique}

This technique is not practiced as frequently as the incremental techniques of composite restoration technique, due to its various disadvantages which would ultimately result in the failure of the restoration. However, some practitioner's, recommend bulkfill technique to reduce stress at the cavo-surface margins [11]. Disadvantages like greater polymerization shrinkage makes it a non-viable option, nevertheless the primary advantage is that the bulk material avoids the formation of incremental voids.

\section{Conventional Incremental Techniques}

\section{a) Horizontal Layering Technique}

In this technique, horizontal placement of $<2.0 \mathrm{~mm}$ thickness of composite restorative material against the prepared cavity surface is done and cured. But the primary disadvantage is that there is an increase of the $\mathrm{C}$-factor, which in turn increase the shrinkage stress [12-14]. 


\section{b) Oblique Layering Technique}

Here, wedge-shaped composite increments are placed against the prepared cavity surface and cured twice, throughout the cavity walls and the occlusal surfaces. The primary advantage in this technique is that there is less $\mathrm{C}$-factor, which prevents the distorted cavity walls which is usually found in other restorative techniques $[11,12]$.

\section{c) Vertical Layering Technique}

In this technique, small increment of composite material is placed vertically from one side of the wall to the other wall. Curing of the material is done from the opposite side of the wall from where the composite is placed, reducing the space at the gingival wall caused by polymerization shrinkage [12-14].

\section{d) Centripetal Buildup Technique}

Initially, a very thin proximal layer is formed and cured, which strengthens the composite and reduces the cervical gap. Further any void which is present would not be a problem as the addition of the next layer of composite fills it, as the composite material is condensed [15].

\section{e) Split-Increment Horizontal Layering Technique}

The horizontally added composite which connects the walls of the prepared cavity with the floor of the cavity produces the highest amount of strength with an unfavorable C-factor ratio of 5, after photo-curing it [12-14]. Horizontal increment is divided into four triangle-shaped portions, with a portion placed against a cavity wall and a part of the floor, one diagonal cut is filled completely with dentin shade composite and cured. Another cut diagonal is filled and cured, one half at a time [16].

\section{f) Successive Cusp Buildup Technique}

Each cusp is built individually, to the occlusal level. Then small increments are added with minimum manipulation is done prevent any material voids. Even though these are time consuming, they provide good strength and excellent aesthetic results [17].

\section{g) Three-Site Technique}

In this technique, light curing of composite with the help of clear matrix along with reflective wedges helps in achieving excellent results. Here, the composite is cured by directing the curing light through the matrix and wedges, to prevent any void at the gingival margin by preventing the polymerization vectors. Addition of wedge shaped composite material in increment is done to further inhibit distortion of cavity walls and reduce the $\mathrm{C}$-factor. Here, polymerization is achieved by cavity walls as well as through the occlusal sides [11].

\section{Esthetic Techniques}

\section{a) Stratified Layering Technique}

High chroma of composite restorative material is placed in the dentin at the center of the preparation and a low chroma composite placed at the cusp walls. This helps in achieving good aesthetic results $[18,19]$.

\section{b) Separate Dentine and Enamel Buildup}

Increments of composite is taken and applied in the form of slopes against the prepared cavity walls up to the level of the amelo-dentinal junction, followed by the addition of the final "enamel" increments. Alternatively, using a dark composite shade gives a better natural appearance for the bulk of the restoration with a translucent or a lighter shade being used for the "enamel" increment [20,21].

\section{c) Dual-Shade Layering Technique}

After the initial procedures which include etching and adhesive application, an addition of opaque composite (dentine material) is added, carved, and cured. Selection of the correct shade with the correct Chroma for the dentin provides the best results. Palatal, proximal, and labial enamel increments are then added over the opacious central core at about half the thickness of residual enamel [22].

\section{d) Polychromatic Layering Technique}

In this technique, different shades of composite material, opalescent are added as needed by the dentist. The main goal in this technique is to achieve the best aesthetic results which should mimic/resemble the natural tooth. Herein, the most widely accepted stratification technique was proposed by Lorenzo Vanini [23].

\section{Conclusion}

Composite restorations are highly favored by the treating dentist because of the varieties of shade available, easy adaptability, good strength and longer life. However, there are many disadvantages like technique sensitive, polymerization shrinkage, inadequate dry area to work causing failure and inadequate light curing (time and depth) being some of them. The three-site technique is the best technique for composite restoration followed by the oblique layering technique as it overcomes the problem of polymerization shrinkage, which is the most common reason for the failure of the restoration.

\section{References}

1. Osborne JW, Norman RD, Gale EN (1990) A 12-year clinical evaluation of two composite resins. Quintessence Int 21: 111-114.

2. Hickel R, Manhart J (2001) Longevity of restorations in posterior teeth and reasons for failure. J Adhes Dent 3: 45-64.

3. Manhart J, Chen H, Hamm G, Hickel R (2004) Buonocore Memorial Lecture. Review of the clinical survival of direct and indirect restorations in posterior teeth of the permanent dentition. Oper Dent 29: 481-508.

4. Macedo G, Raj V, Ritter AV (2006) Longevity of anterior composite restorations. J Esthet Restor Dent 18: 310-311.

5. Zachrisson BU, Mjör IA (1975) Remodeling of teeth by grinding. Am J Orthod 68: 545-553.

6. Heymann HO (1997) Conservative concepts for achieving anterior esthetics. J Calif Dent Assoc 25: 437-443. 
7. Leonard RH, Bentley C, Eagle JC, Garland GE, Knight MC, et al. (2001) Night guard vital bleaching: A long-term study on efficacy, shade retention. Side effects, and patients' perceptions. J Esthet Restor Dent 13: 357-369.

8. Ritter AV, Leonard RH Jr, St Georges AJ, Caplan DJ, Haywood VB (2002) Safety and stability of night guard vital bleaching: 9 to 12 years post-treatment. J Esthet Restor Dent 14: 275-285.

9. Sundfeld RH, Croll TP, Briso AL, de Alexandre RS, Sundfeld Neto D (2007) Considerations about enamel micro abrasion after 18 years. Am J Dent 20: 67-72.

10. Donly KJ, Jensen ME (1986) Posterior composite polymerization shrinkage in primary teeth: An in vitro comparison of three techniques. Pediatr Dent 8: 209-212.

11. Giachetti L, Scaminaci Russo D, Bambi C, Grandini R (2006) A review of polymerization shrinkage stress: Current techniques for posterior direct resin restorations. J Contemp Dent Pract 7: 79-88.

12. Spreafico RC, Gagliani M (2000) Composite resin restorations on posterior teeth. In: Roulet JF, Degrange M, editors. Adhesion: The Silent Revolution in Dentistry. Chicago: Quintessence Publishing pp. 253-276.

13. Lutz F, Krejci I, Barbakow F (1991) Quality and durability of marginal adaptation in bonded composite restorations. Dent Mater 7: 107-113.

14. Tjan AH, Bergh BH, Lidner C (1992) Effect of various incremental techniques on the marginal adaptation of class II composite resin restorations. J Prosthet Dent 67: 62-66.
15. Dickinson GL, Leinfelder KF, Mazer RB, Russell CM (1990) Effect of surface penetrating sealant on wear rate of posterior composite resins. J Am Dent Assoc 121: 251-255.

16. Hassan KA, Khier SE (2007) Split-increment technique: An alternative approach for large cervical composite resin restorations. J Contemp Dent Pract 8: 121-128.

17. Mackenzie L, Shortall AC, Burke FJ (2009) Direct Posterior composites: A practical guide. Dent update 36: 71-72, 74-76,79-80.

18. Vanini L (1996) Light and color in anterior composite restorations. Pract Periodontics Aesthet Dent 8: 673-682.

19. Ritter AV (2001) Posterior resin-based composite restorations: Clinical recommendations for optimal success. J Esthet Restor Dent 13: 88-99.

20. Javaheri DS (2001) Placement technique for direct posterior composite restorations. Pract Proced Aesthet Dent 13: 195-200.

21. Summitt JB, Robbins JW, Hilton TJ, Schwart RS, Santos JD (2006) Fundamentals of Operative Dentistry: A Contemporary Approach. Illinois, USA: Quintessence Books pp. 289-339.

22. Manauat J, Salat A (2013) Layers: An Atlas of Composite Resin Stratification. Quintessence Publishing Co Ltd, London, USA.

23. Chiche GJ, Pinault A. Esthetics of Anterior Fixed Prosthodontics. London, USA.

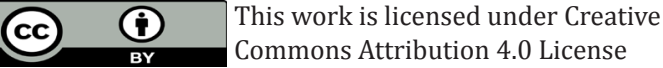

To Submit Your Article Click Here:

Submit Article

DOI: 10.32474/MADOHC.2019.03.000174

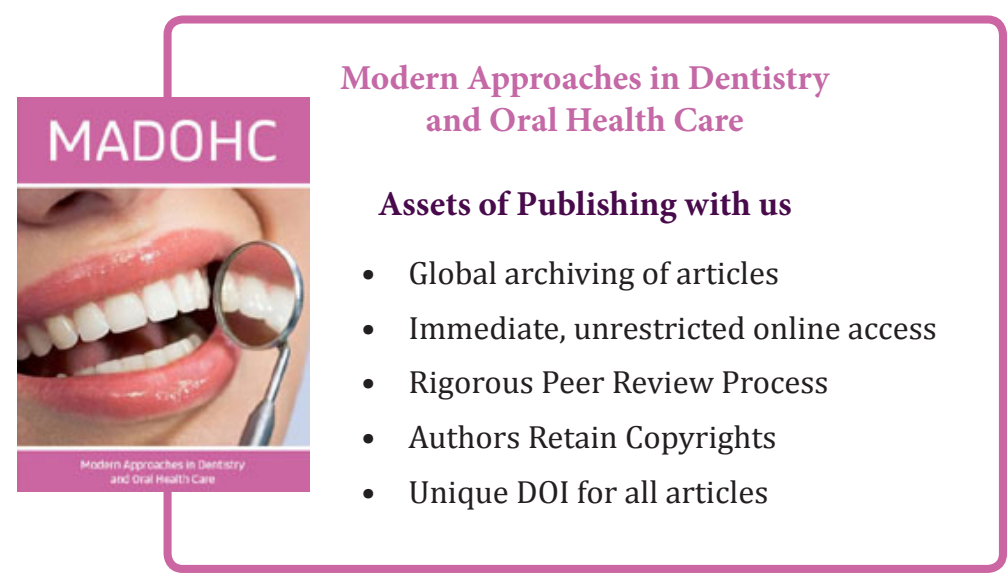

